\title{
Treatment of Multifocal Multisystem BRAF Positive Langerhans Cell Histiocytosis with Cladribine, Surgery and Allogenic Stem Cell Transplantation
}

\author{
Filip Gabalec ${ }^{1, *}$, Martin Šimkovič ${ }^{1}$, Alžběta Zavřelová ${ }^{1}$, Petra Kašparová2, Paula Morávková3, \\ Marcela Kopáčová ${ }^{3}$, Václav Masopust ${ }^{4}$, Pavel Žák ${ }^{1}$, Jan Čáp ${ }^{1}$, Jakub Radocha ${ }^{1}$
}

\begin{abstract}
Langerhans cell histiocytosis $(\mathrm{LCH})$ is a very rare disease in adults and as well a very rare cause of sellar expansion. The clinical presentation can be heterogeneous, from a single bone lesion to potentially fatal, widespread disease. We describe the difficulties with the diagnosis and treatment of $\mathrm{LCH}$ as well as successful treatment with cladribine chemotherapy and allogeneic stem cell transplantation.
\end{abstract}

\section{KEYWORDS}

histiocytosis; transplantation, stem cell; cladribine; hypopituitarism

\section{AUTHOR AFFILIATIONS}

1 4th Department of Internal Medicine - Haematology, University Hospital Hradec Králové, Czech Republic and Charles University, Faculty of Medicine in Hradec Králové, Czech Republic

2 Fingerland's Department of Pathology, University Hospital Hradec Králové, Czech Republic and Charles University, Faculty of Medicine in Hradec Králové, Czech Republic

${ }^{3}$ 2nd Department of Internal Medicine - Gastroenterology, University Hospital Hradec Králové, Czech Republic and Charles University, Faculty of Medicine in Hradec Králové, Czech Republic

${ }^{4}$ Neurosurgery Clinic, Central Military Hospital Prague, Prague, Czech Republic

* 4th Department of Internal Medicine; University Hospital Hradec Králové

Sokolská 581, 50005 Hradec Králové, Czech Republic; e-mail: filip.gabalec@fnhk.cz

Received: 24 October 2017

Accepted: 20 December 2017

Published online: 23 April 2018

Acta Medica (Hradec Králové) 2017; 60(4): 152-156

https://doi.org/10.14712/18059694.2018.11

(c) 2017 The Authors. This is an open-access article distributed under the terms of the Creative Commons Attribution License (http://creativecommons.org/licenses/by/4.0), which permits unrestricted use, distribution, and reproduction in any medium, provided the original author and source are credited. 


\section{BACKGROUND}

Langerhans cell histiocytosis (LCH) is a clonal proliferative disease. $\mathrm{LCH}$ is a very rare disease in adults with an incidence 1-2 adults per million per year. The clinical presentation can be heterogeneous, from a single bone lesion to potentially fatal, widespread disease. The most frequently affected systems are bones, lung, and skin. LCH that presents as endocrine disorders or as a cause of a sellar expansion is rather rare and can be often misdiagnosed. Central nervous system is affected in $6 \%$ of patients with LHC, mostly the hypothalamo-pituitary region and pineal gland, cerebellum and basal ganglia (1). Usually, patients suffer from central diabetes insipidus and pituitary stalk is thicker on imagining. We describe the difficulties with the evaluation and the treatment of LCH as well as successful treatment with cladribine chemotherapy and allogeneic stem cell transplantation.

\section{CASE PRESENTATION}

42 years old Caucasian woman has had amenorrhea for 2 years and higher intake of fluids (5-7 liters/day) for 6 years prior to referral. Non-functioning pituitary expansion with pituicytoma appearance was found on MRI. She was followed up for almost 3 years. Panhypopituitarism developed during the follow-up and replacement therapy with

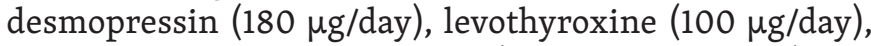
ethinylestradiol/levonorgestrel (30 $\mu \mathrm{g} / 150 \mu \mathrm{g} / \mathrm{day})$ and hydrocortisone (30-50 mg/day) was initiated. She did not take other medication. The patient was referred to biopsy of sellar expansion, as slow enlargement of the pituitary expansion occurred. No relevant family history was reported. Her past medical history included a notion of asymptomatic mild mitral valve insufficiency. She is a non-smoker, not drinking alcohol and she has no allergies or autoimmune disorders. Physical examination was physiological except obesity. No sensoric or motoric neurological deficit was found.

\section{INVESTIGATION}

An open (craniotomy) biopsy of the suprasellar lesion (Fig. 1) was inconclusive for the first time and complicated with transient manifest left hemiparesis due to small acute ischemia in basal ganglia (revealed by MRI). The biopsy was repeated in one month. This time histology showed small foci with large cells positive for CD1a and S100 in imunohistochemical analysis (Fig. 2). Also, positivity for CD68 and mild positivity for BRAF was present. GFAP was negative. The conclusion of Langerhans cell histiocytosis was made by two independent pathologists. She was admitted to our centre for further evaluation. Staging of the disease revealed suprasellar expansion, skeletal and retrobulbar infiltration, lymphadenopathy along the right internal carotid artery and retroperitoneal and mediastinal lymphadenopathy with FDG avidity on fluorodeoxyglucose-positron emission computer tomography scanning (FDG-PET/CT) (Fig. 3A). The bone marrow biopsy did

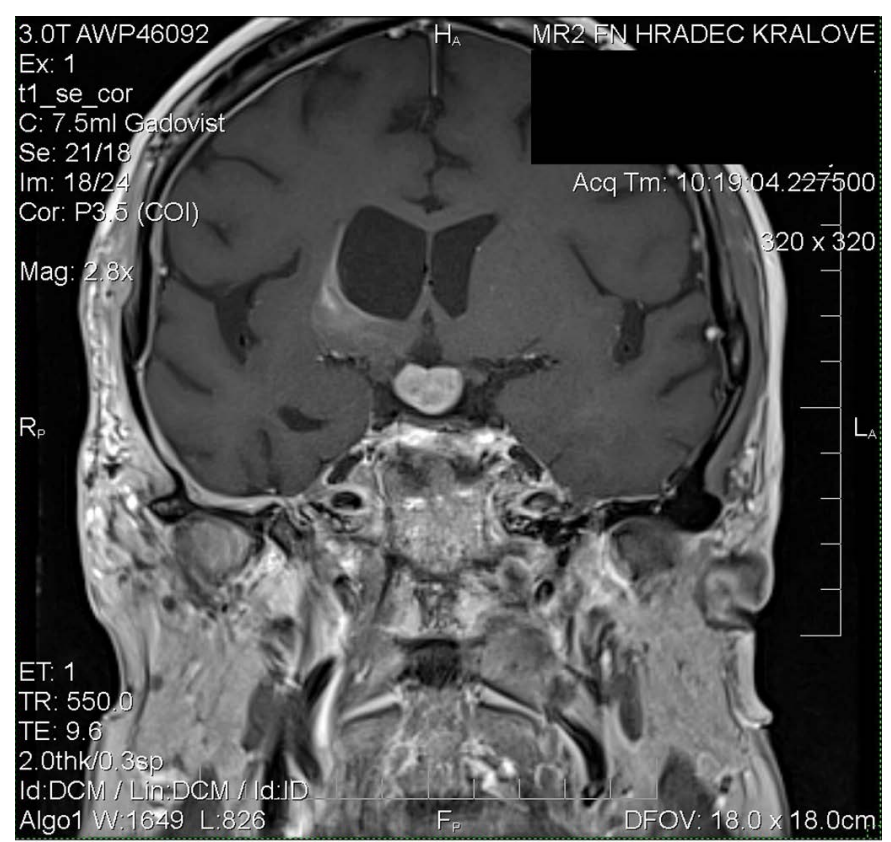

Fig. 1 Magnetic resonance imagining showing suprasellar expansion due to Langerhans cell histiocytosis.

not reveal an infiltration of bone marrow. Retrospectively, BRAF mutation expression in codon 600 and 601 was evaluated by PCR with consequent reverse hybridization (kit BRAF 600/601 StripAssay - ViennaLab). Mutation in gene BRAF, NM_004333.4: c.1799T>A, p.V600E was present.

\section{TREATMENT AND FURTHER INVESTIGATION}

The patient received five cycles (six planned) of cladribine monotherapy ( $0.14 \mathrm{mg} / \mathrm{kg}$ for 5 days in each cycle). However, prolonged neutropenia and gastrointestinal and repeated urinary infections led to premature termination of the treatment. A complete regression of previously described lymphadenopathy and tumour infiltration was achieved on subsequent PET/CT restaging. Unfortunately, new FDG positive lesion approximately $40 \mathrm{~cm}$ in proximal jejunum was found with bowel dilatation up to $7 \mathrm{~cm}$ (Fig. 3B). Small lymphadenopathy with an accumulation of FDG was found locally. Double balloon enteroscopy showed tight stenosis $(4 \mathrm{~mm})$ of the oral jejunum due to tumour infiltration (Fig. 4). Prestenotic dilatation with impacted food was present. Biopsy confirmed infiltration by Langerhans cell histiocytosis. As no other infiltration was found on PET/CT and bone marrow biopsy was negative, resection of infiltrated part of jejunum with end-to-end anastomosis was performed and the patient was indicated for myeloablative allogeneic stem cell transplantation from matched unrelated donor. A conditioning regimen BuFluTG included (Fludarabine $40 \mathrm{mg} / \mathrm{m}^{2}$ from day -7 to day -3 , i.v. Busulfan $3.2 \mathrm{mg} / \mathrm{kg}$ from day -7 to day -5 and rATG (Thymoglobulin) $3 \mathrm{mg} / \mathrm{kg}$ from day -2 to day -1 . She received transplantation from the male 10/10 donor (dose $6.0 \times 10 / 6 / \mathrm{kg}$ CD34+ cells). Transplantation was complicated with sepsis, originated from the gastrointestinal tract. Frequent monitoring of sodium and therapy amendment was required due to hypopituitarism and higher require- 

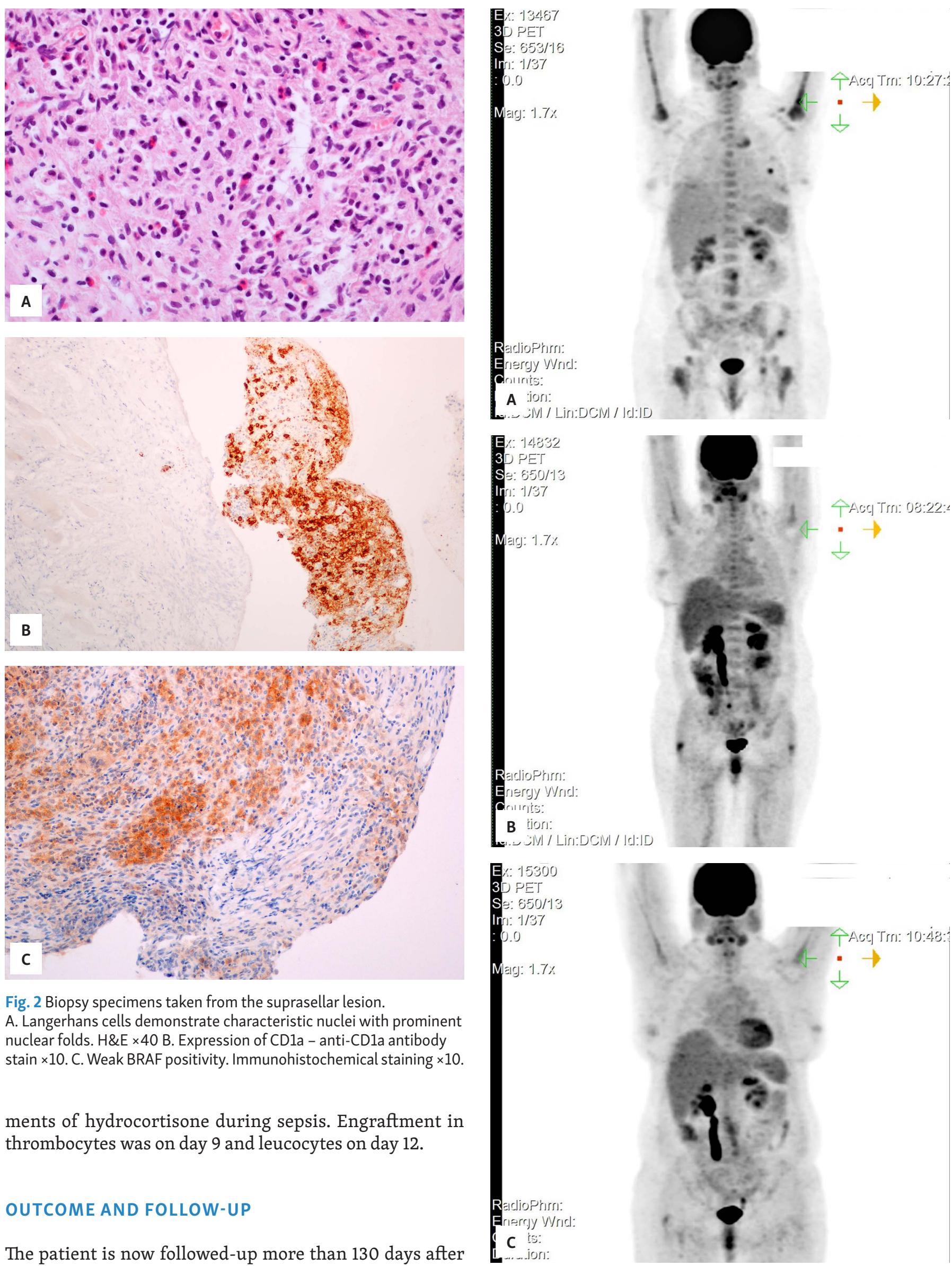

The patient is now followed-up more than 130 days after transplantation without serious complications and signs of the disease. PET/CT was negative after surgery (Fig. 3C) and in 3 months after transplantation. Next PET/CT is planned at 12 months after transplantation.

Fig. 3 A. Fluorodeoxyglucose-positron emission tomography scanning (FDG-PET) before treatment. B. FDG-PET after Cladribine chemotherapy - regression of the previous tumor, new infiltration of jejunum is present. C. FDG-PET after jejunum resection. 


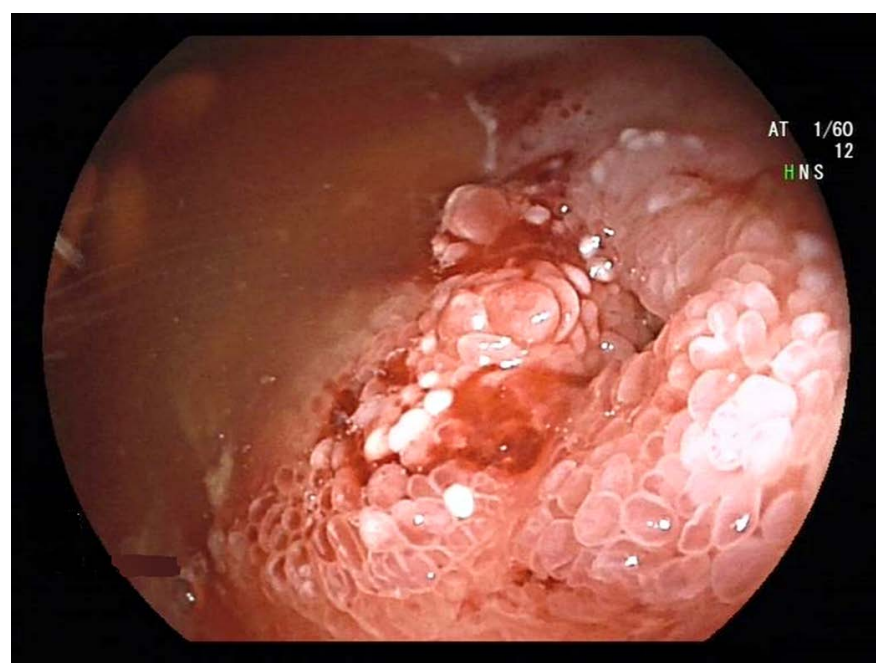

Fig.4 Double balloon enteroscopy showed tight stenosis ( $4 \mathrm{~mm}$ ) of the oral jejunum due to tumour infiltration.

\section{DISCUSSION}

Langerhans cell histiocytosis (LCH) is a rare histiocytic disorder of unknown etiology. LCH is characterized by monoclonal proliferation of Langerhans cells derived from myeloid progenitor cells that express the CD34 surface antigen. As in our case, somatic oncogen $\mathrm{BRAF}^{\mathrm{V} 600 \mathrm{E}}$ mutation is present in $25-60 \%$ of cases. Patients with the BRAF ${ }^{\mathrm{V} 600 \mathrm{E}}$ mutation have a higher occurrence of diabetes insipidus and have more severe disease than those with wild-type BRAF. Also, resistance to combined therapy (vinblastine and corticosteroids) is more common. Second-line chemotherapy and rescue therapy is necessary in $19 \%$ of cases and reactivation is more common (2).

Hypothalamus-pituitary-adrenal axis infiltration is present in up to $50 \%$ of LCH. The most common disorder is diabetes insipidus (DI). The frequency of DI is $30-40 \%$ and $94 \%$ if other pituitary hormone deficiencies exist. The diagnosis can be difficult. It is important to exclude LCH before making the diagnosis of idiopathic DI. Whole body imaging is indicated in the presence of thickened pituitary stalk to find potential extracerebral place for biopsy (3). FDG-PET seems to be a good tool in these cases. Also, FDGPET scanning is used for assessing the extent of LHC, its progression and the response to treatment $(4,5)$.

Our patient had hypopituitarism. Other hormone deficiencies are present less frequently - in up to $20 \%$ of LCH cases and in up to $60 \%$ when DI is present. These deficiencies are often irreversible even after treatment of LCH. Prompt hormone replacement therapy is mandatory, and continuous follow-up is needed to detect deficiencies that might evolve later (6).

There is no specific therapy or universally accepted guidelines for treatment of this orphan disease in adults. Validated therapeutic options are outlined in recent review by Haroche et al. (7). The primary treatment modalities for LCH include local excision of the lesion, corticoid therapy, chemotherapy, radiotherapy, and immunotherapy with anti-CDla monoclonal antibodies or BRAF inhibition if present. In general, the localized disease requires minimal treatment and is considered as having a good prognosis. Multi-systemic and multi-focal disease with involvement of liver, spleen, lung and bone-marrow are considered as a higher risk. The data regarding the treatment of the central nervous system involvement with LCH are very limited. No drug or regimen has been proved superior to the others. Cladribine (2-CdA) is a promising agent in this setting as previously reported also with a review of previous studies (8). Cladribine has good bioavailability in the CNS. A total of six cycles of cladribine monotherapy can be administered with respect to the good profile of toxicity in this indication. However, in our case, only five cycles were administrated and chemotherapy stopped earlier due to prolonged neutropenia and infectious complications. As the patient had persistent disease after front-line treatment, she was considered as a high risk further. Surgery seemed as an optimal option to solve out the bowel stenosis due to the tumour. Gastrointestinal involvement in LCH commonly includes duodenum or colon in a multifocal pattern with superficial erosions or bleeding ulcers. It appears usually in multi-systemic diseases. Isolated LCH in a small bowel is very rare. Case reports were reviewed by Shankar et al. (9), reporting only one case in adults (10).

Myeloablative allogeneic stem cell transplantation (allo-HSCT) is an option in high-risk LCH with persistent disease and was reported in the pediatric population (11-13). Data for adults are rather scarce. The worlds' first adult case of multisystem LCH with pulmonary involvement and thrombocytopenia with absent radii successfully treated with allo-HSCT was reported in 2006 (14). The other was reported in Spain (15). No trials exist for treatment of LCH in adult population. With limited accuracy the treatment strategies are translated from pediatric experience to adult population. Even in the pediatric population the data are limited. Steiner et al. described successful treatment of 7 out of 9 children with allo-HSCT (12). Cooper et al. reported other 3 cases of LCH successfully treated with allo-HSCT (13). All previously mentioned patients were under the age of 24 months. Reduced intensity conditioning is preferred in these cases to reduce toxicity. In our case, front-line therapy with cladribine was unsuccessful, so we continued with surgery and allo-HSCT. In the future, the position of allo-HSCT may have limited indication for $\mathrm{LCH}$ following the discovery and wider use of BRAF inhibitors and the increased use of targeted therapies like vemurafenib for example.

\section{LEARNING POINTS}

- Histiocytosis is an orphan disease and should be considered in differential diagnosis as any organ or system can be affected.

- Histiocytotis should be excluded in cases of diabetes insipidus of unknown aetiology and whole body imaging is indicated in the presence of thickened pituitary stalk to find potential extracerebral place for biopsy.

- Rare small bowel infiltration by Langerhans cell histiocytosis is presented.

- Allogeneic haematopoetic stem cell transplantation is an option for the second-line treatment. 
FUNDING STATEMENT

Supported by program PROGRES Q40/08 and by MH CZ DRO (UHHK, 00179906).

\section{DECLARATION OF INTEREST}

There is no conflict of interest.

\section{PATIENT CONSENT}

Written informed consent has been obtained from the patient. Signed copy of the consent is available to the publisher.

\section{REFERENCES}

1. Imashuku S, Kudo N, Kaneda S, et al. Treatment of patients with hypothalamic-pituitary lesions as adult-onset Langerhans cell histiocytosis. International Journal of Hematology 2011; 94(6): 556-560.

2. Heritier S, Emile JF, Barkaoui MA, et al. BRAF Mutation Correlates With High-Risk Langerhans Cell Histiocytosis and Increased Resistance to First-Line Therapy. Journal of Clinical Oncology: Official Journal of the American Society of Clinical Oncology 2016; 34(25): 3023-3030.

3. Catford S, Wang YY, Wong R. Pituitary stalk lesions: systematic review and clinical guidance. Clinical Endocrinology 2016; 85(4): 507-521.

4. Pekic S, Popovic V. Diagnosis of endocrine disease: Expanding the cause of hypopituitarism. European Journal of Endocrinology 2017; 176(6): R269-R282.

5. Phillips M, Allen C, Gerson P, McClain K. Comparison of FDG-PET scans to conventional radiography and bone scans in management of Langerhans cell histiocytosis. Pediatric Blood \& Cancer 2009; 52(1): 97-101.

6. Makras P, Alexandraki KI, Chrousos GP, Grossman AB, Kaltsas GA. Endocrine manifestations in Langerhans cell histiocytosis. Trends in Endocrinology and Metabolism: TEM 2007; 18(6): 252-257.

7. Haroche J, Cohen-Aubart F, Rollins BJ, et al. Histiocytoses: Emerging Neoplasia behind Inflammation. The Lancet Oncology 2017; 18(2): e113-e125.

8. Adam Z, Szturz P, Vanicek J, et al. Cladribine (2-chlorodeoxyadenosine) in frontline chemotherapy for adult Langerhans cell histiocytosis: A single-center study of seven cases. Acta Oncologica 2013; 52(5): 994-1001.

9. Shankar U, Prasad M, Chaurasia OP. A rare case of langerhans cell histiocytosis of the gastrointestinal tract. World Journal of Gastroenterology 2012; 18(12): 1410-1413.

10. Lee-Elliott C, Alexander J, Gould A, Talbot R, Snook JA. Langerhan's cell histiocytosis complicating small bowel Crohn's disease. Gut 1996; 38(2): 296-298.

11. Akkari V, Donadieu J, Piguet C, et al. Hematopoietic stem cell transplantation in patients with severe Langerhans cell histiocytosis and hematological dysfunction: experience of the French Langerhans Cell Study Group. Bone Marrow Transplantation 2003; 31(12): 1097-1103.

12. Steiner M, Matthes-Martin S, Attarbaschi A, et al. Improved outcome of treatment-resistant high-risk Langerhans cell histiocytosis after allogeneic stem cell transplantation with reduced-intensity conditioning. Bone Marrow Transplantation 2005; 36(3): 215-225.

13. Cooper N, Rao K, Goulden N, Webb D, Amrolia P, Veys P. The use of reduced-intensity stem cell transplantation in haemophagocytic lymphohistiocytosis and Langerhans cell histiocytosis. Bone Marrow Transplantation 2008; 42(Suppl 2): S47-50.

14. Ingram W, Desai SR, Gibbs JS, Mufti G. Reduced-intensity conditioned allogeneic haematopoietic transplantation in an adult with Langerhans' cell histiocytosis and thrombocytopenia with absent radii. Bone Marrow Transplantation 2006; 37(7): 713-715.

15. Xicoy B, Ribera JM, Batlle M, Feliu E. [Sustained remission in an adult patient with Langerhans cell histiocytosis following T-cell depleted allogenic cell transplantation]. Medicina Clinica 2006; 127(18): 716. 